Supporting Information

\title{
Electroactive Covalent Organic Frameworks/Carbon Nanotubes Composites for Electrochemical Sensing
}

Linyu Wang, Yi Xie, Yuxi Yang, Huihui Liang, Li Wang* and Yonghai Song*

Key Laboratory of Functional Small Organic Molecule, Ministry of Education, Key Laboratory of

Chemical Biology, Jiangxi Province, College of Chemistry and Chemical Engineering, Jiangxi Normal University, Nanchang, 330022, China.

*Corresponding author: Tel/Fax: +86 0791 88120861. E-mail: yhsonggroup@hotmail.com (Y. Song) and lwang@jxnu.edu.cn (L. Wang). 


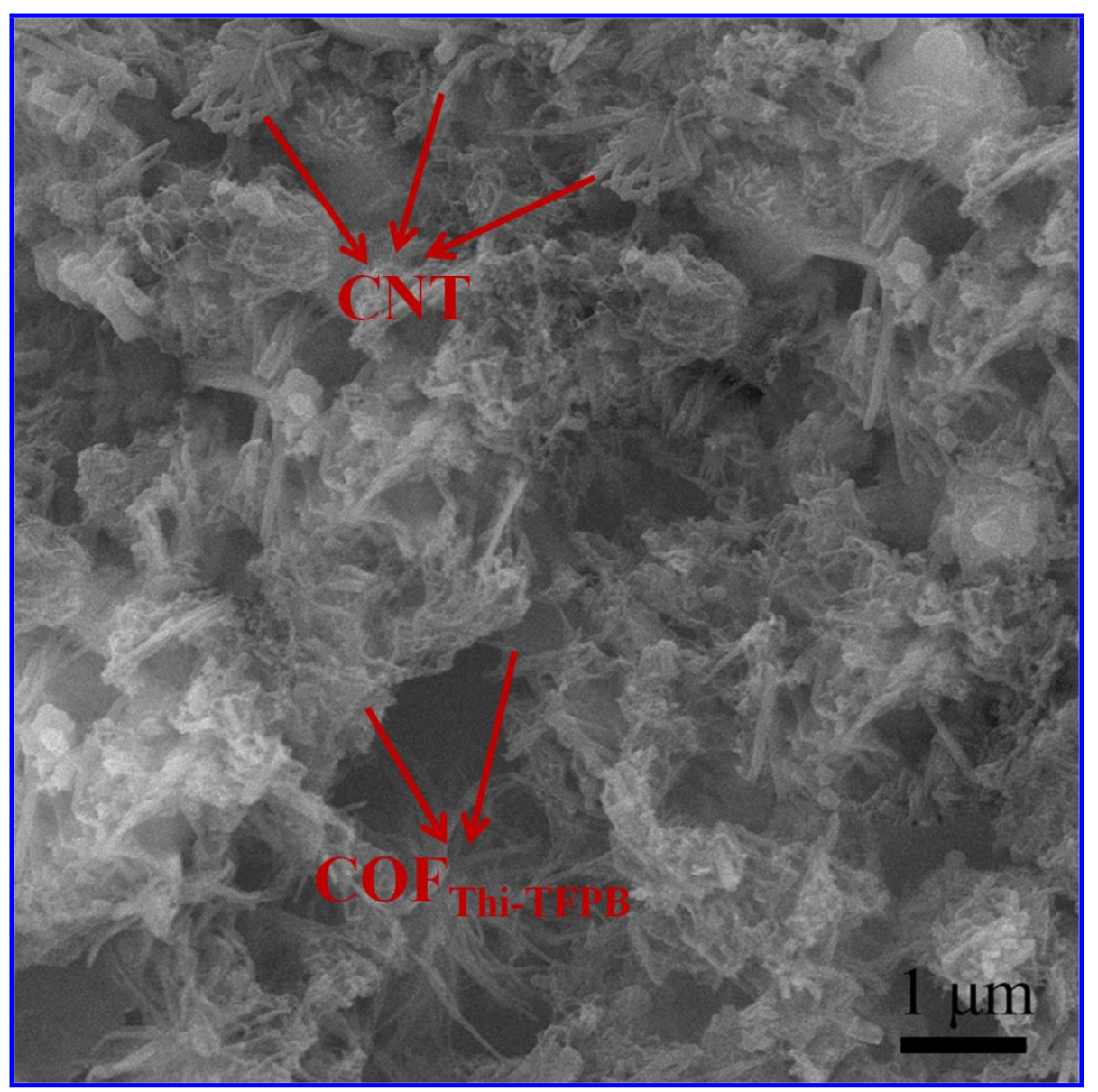

Figure S1. SEM image of the $\mathrm{COF}_{\text {Thi-TFPB }}-\mathrm{CNT} / \mathrm{GCE}$. 


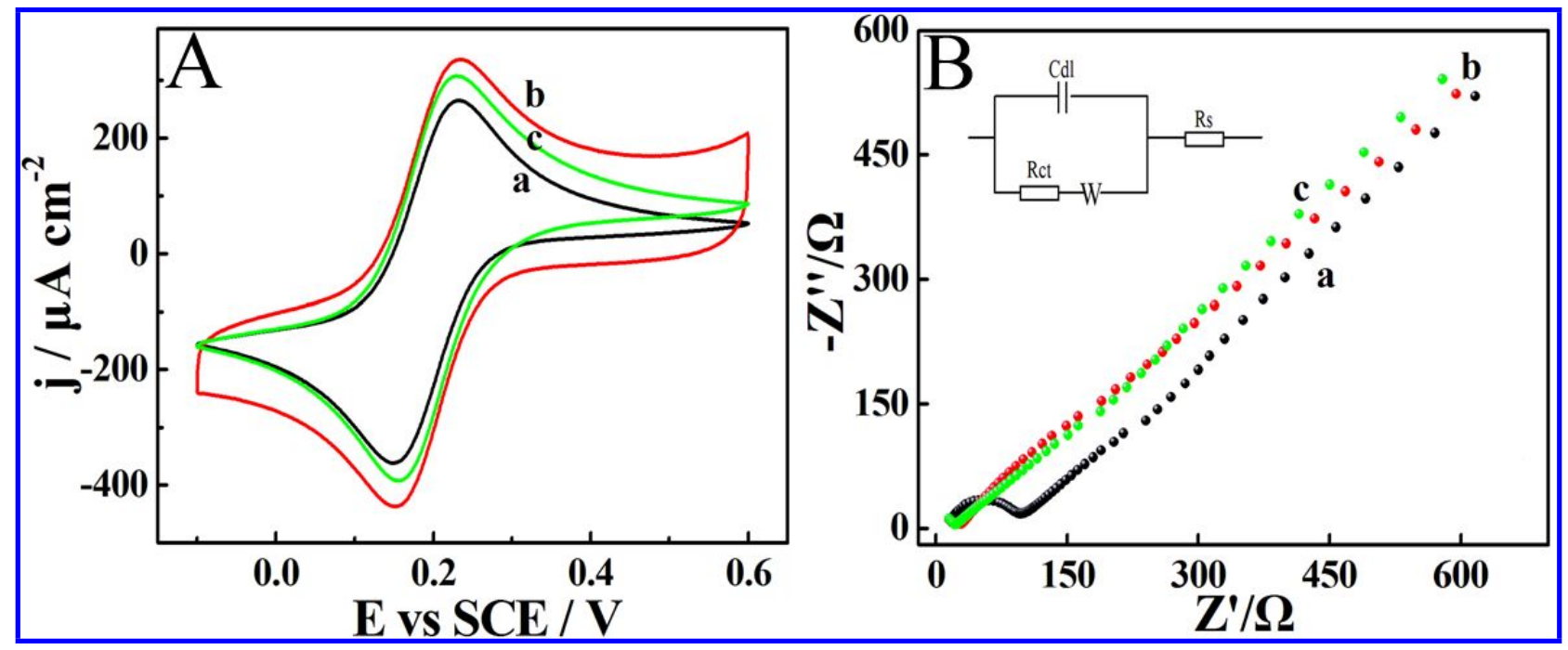

Figure S2. (A) CVs of GCE (curve a), $\mathrm{COF}_{\mathrm{Thi}-\mathrm{TFPB}} / \mathrm{GCE}$ (curve b) and $\mathrm{COF}_{\mathrm{Thi}-\mathrm{TFPB}}-\mathrm{CNT} / \mathrm{GCE}$ (curve c) in $5.0 \mathrm{mM} \mathrm{K}_{3}\left[\mathrm{Fe}(\mathrm{CN})_{6}\right]$ and $0.1 \mathrm{M} \mathrm{KCl}$ solution at $50 \mathrm{mV} \mathrm{s}^{-1}$. (B) EIS of GCE (curve a), $\mathrm{COF}_{\text {Thi-TFPB }} / \mathrm{GCE}$ (curve b) and $\mathrm{COF}_{\text {Thi-TFPB }} \mathrm{CNT} / \mathrm{GCE}$ (curve c) in $0.1 \mathrm{M} \mathrm{KCl}$ with $5 \mathrm{mM}$ $\left[\mathrm{Fe}(\mathrm{CN})_{6}\right]^{3-/ 4-}$. Insert is the Randles equivalence circuit model to fit the EIS data. 


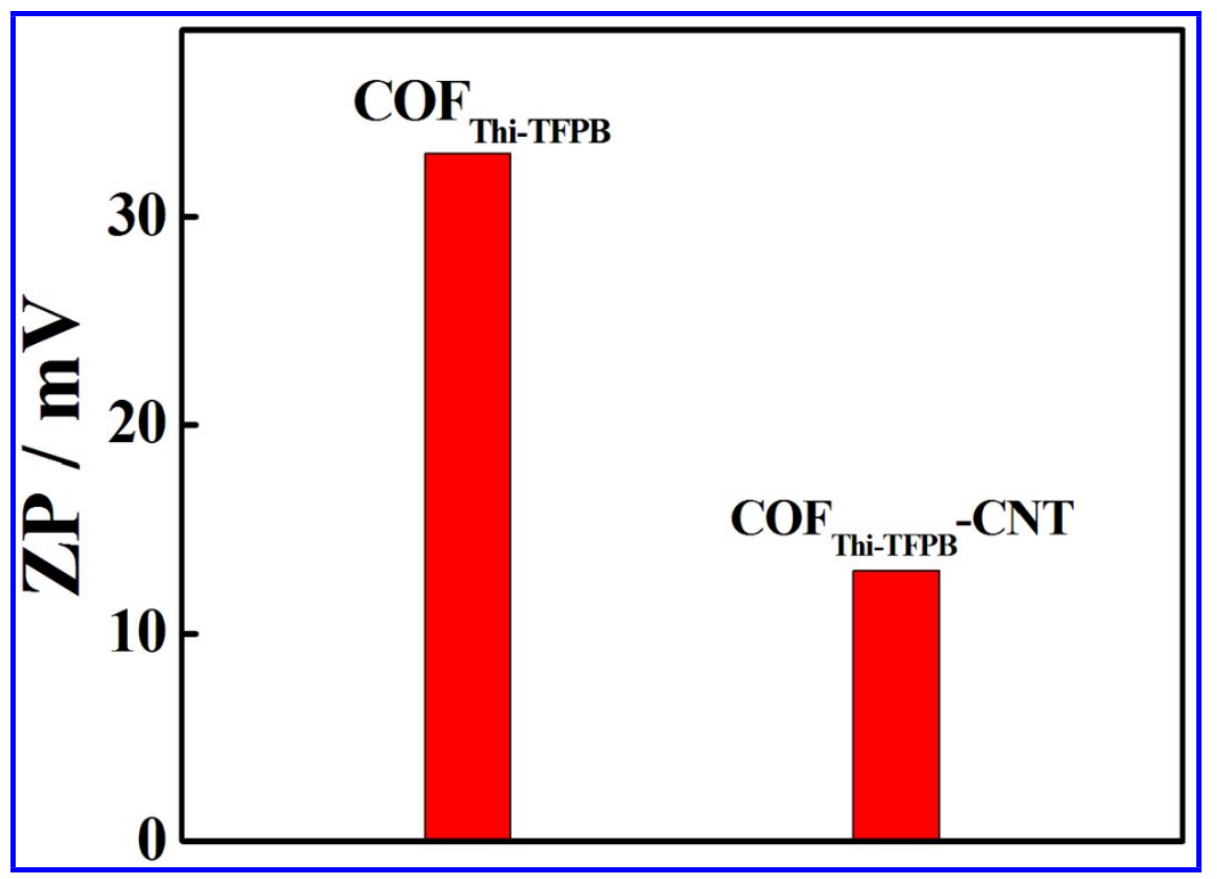

Figure S3. Zeta potential of $\mathrm{COF}_{\mathrm{Thi}-\mathrm{TFPB}}$ and $\mathrm{COF}_{\mathrm{Thi}-\mathrm{TFPB}}-\mathrm{CNT}$. 


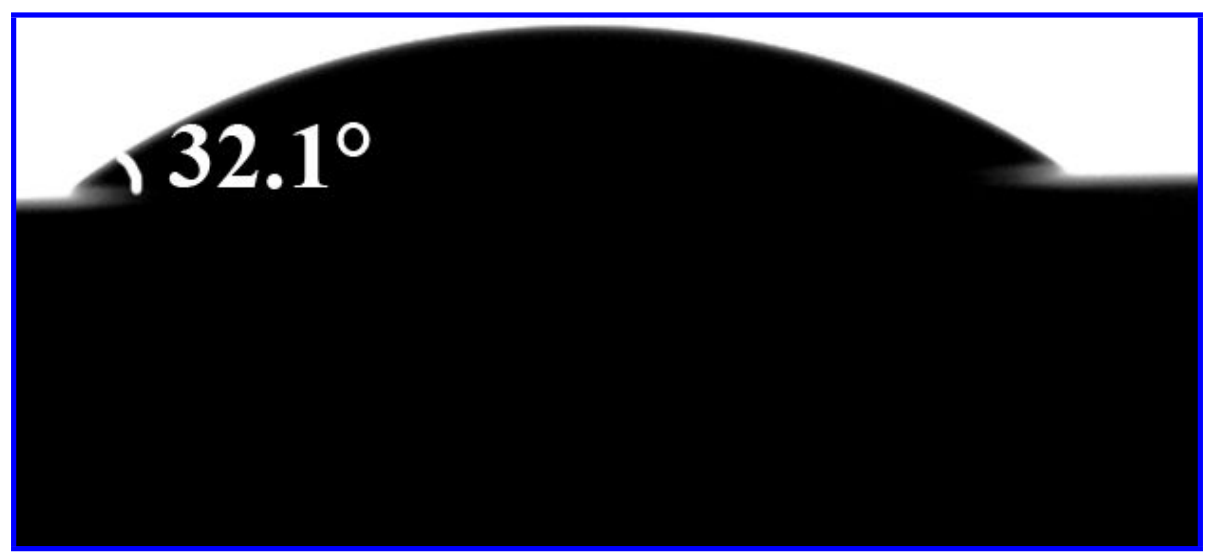

Figure S4. Contact angle of $\mathrm{COF}_{\text {Thi-TFPB }}$. The contact angle of $\mathrm{COF}_{\text {Thi-TFPB }}$ was only $32.1^{\circ}$. 


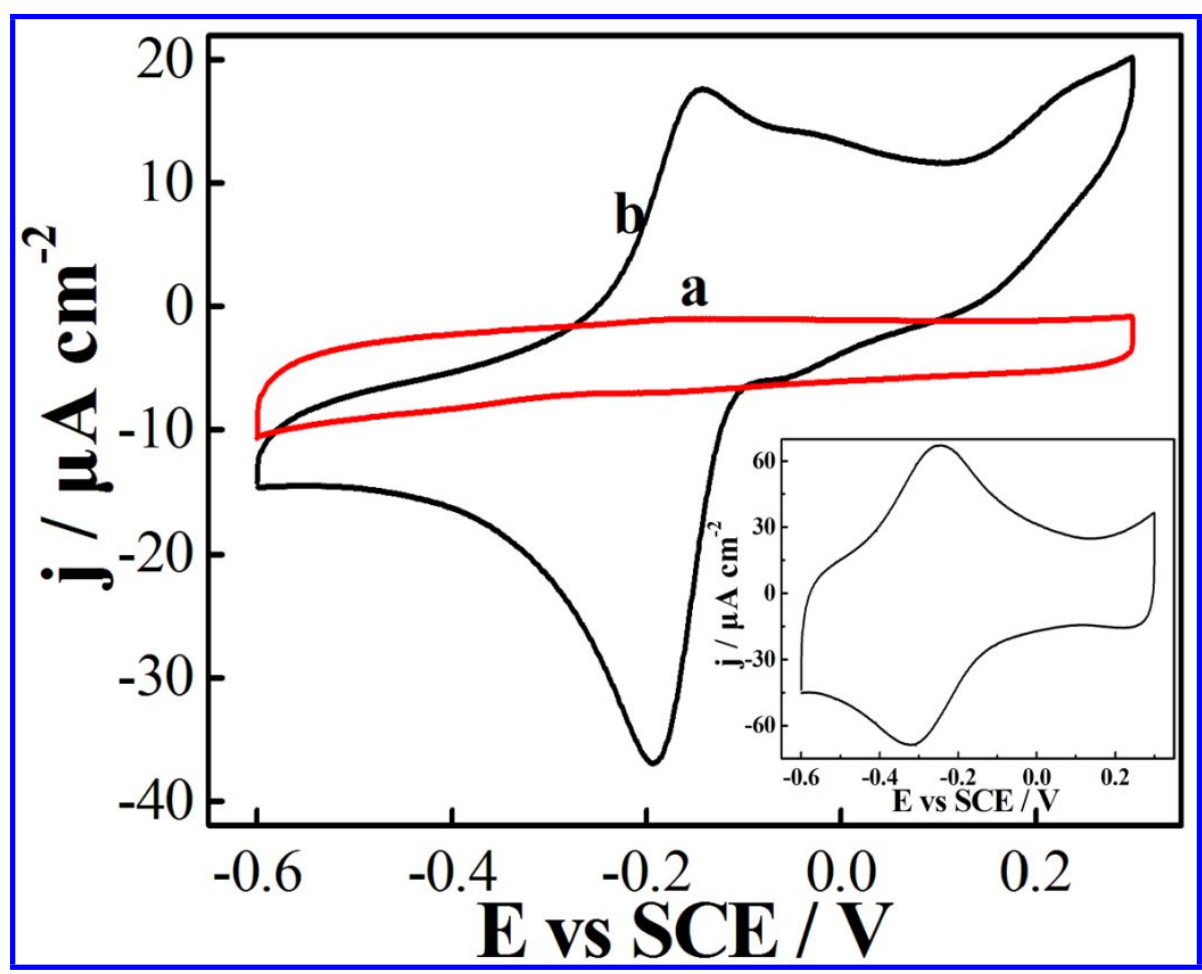

Figure S5. CV curves of GCE (curve a) and $\mathrm{COF}_{\text {Thi-TFPB }} / \mathrm{GCE}$ (curve b) in $0.2 \mathrm{M} \mathrm{N}_{2}$-saturated PBS. Insert is the $\mathrm{CV}$ curve of $\mathrm{COF}_{\text {Thi-TFPB }}-\mathrm{CNT} / \mathrm{GCE}$ in $0.2 \mathrm{M} \mathrm{N}_{2}$-saturated PBS. 


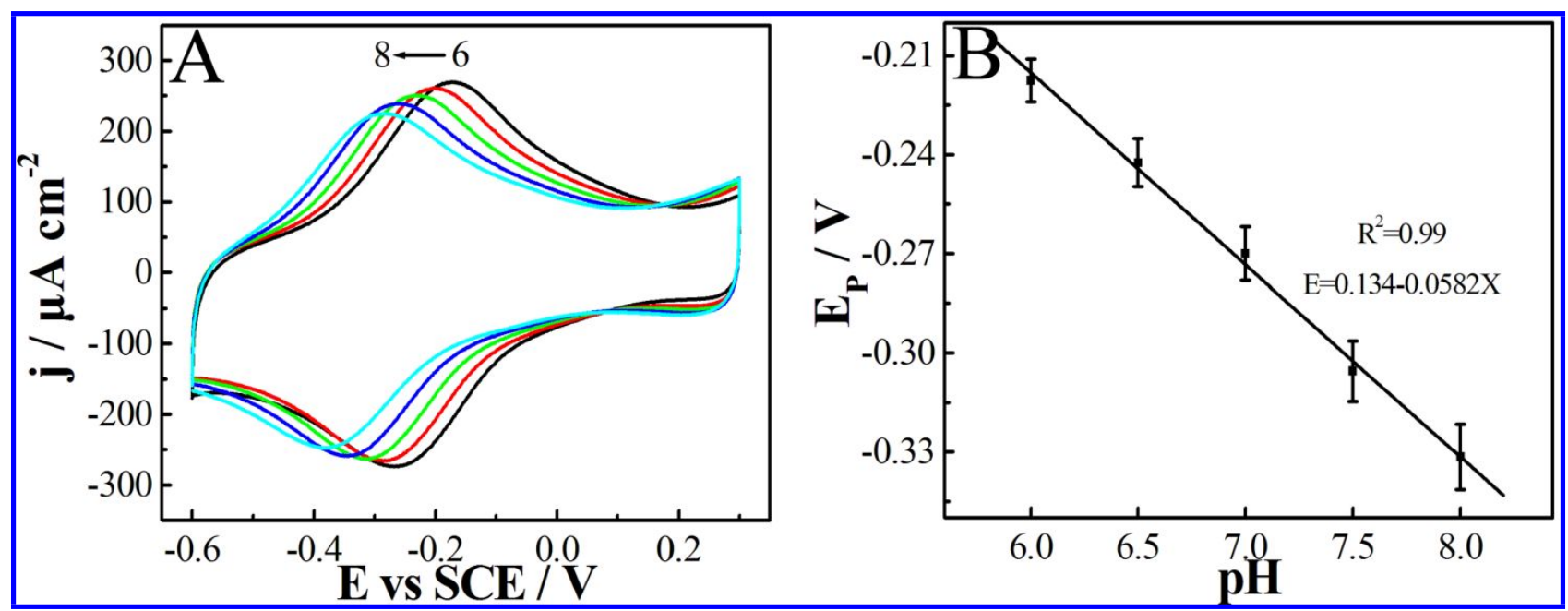

Figure S6. (A) CVs of $\mathrm{COF}_{\mathrm{Thi}-\mathrm{TFPB}}-\mathrm{CNT} / \mathrm{GCE}$ in $0.2 \mathrm{M}$ nitrogen-saturated PBS with different $\mathrm{pH}$ (6 to 8). (B) Plot of peak potential versus $\mathrm{pH}$. 


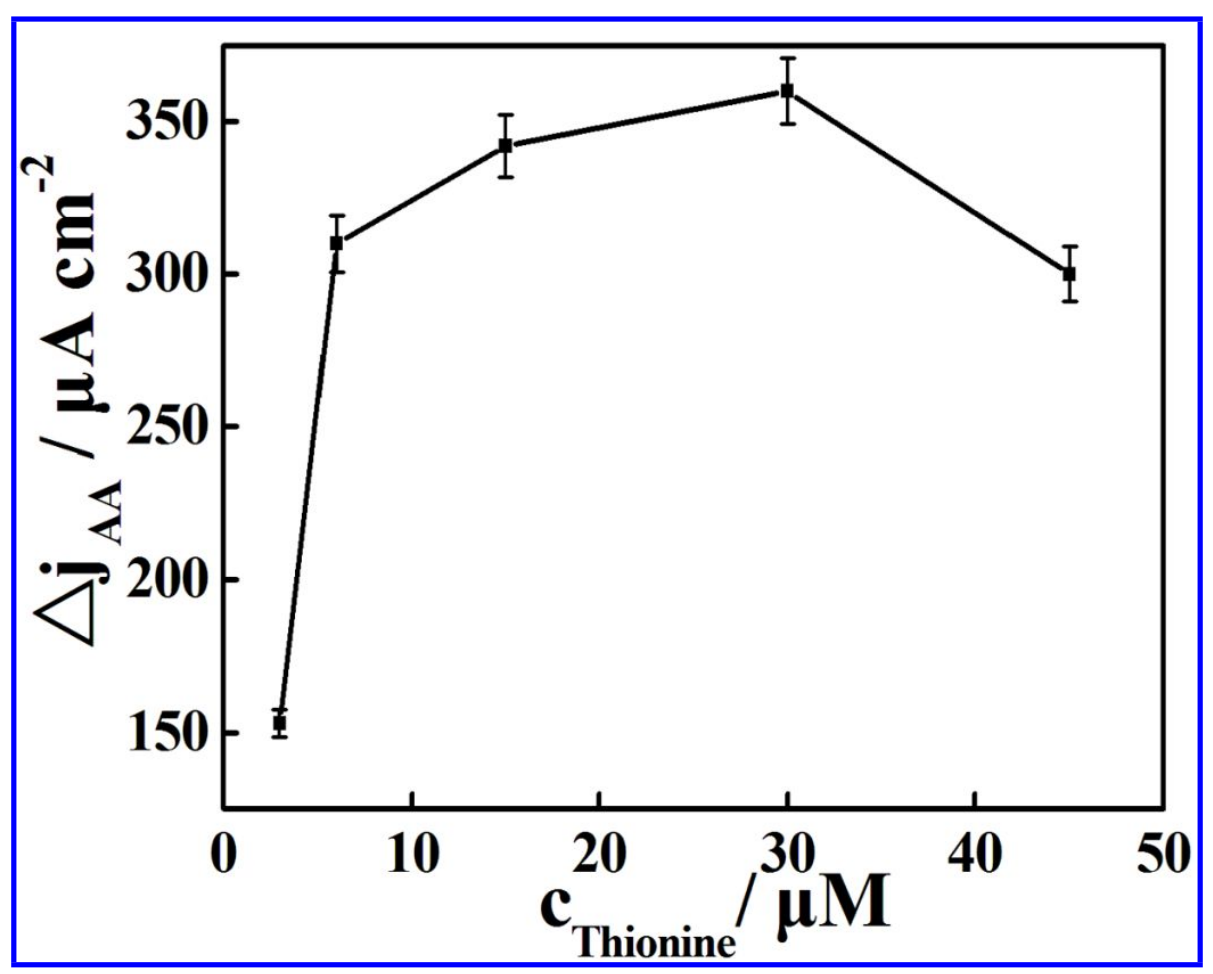

Figure S7. Influence of different concentration of thionine used to synthesize $\mathrm{COF}_{\mathrm{Thi}-\mathrm{TFPB}} \mathrm{CNT}$ on the catalysis of AA. (The concentration ratio of thionine and 1,3,5-Tris(p-formylphenyl)benzene was $3: 2$. The quantity of CNT was controlled as $10.5 \mathrm{mg}$. The concentration of $\mathrm{COF}_{\mathrm{Thi}-\mathrm{TFPB}}-\mathrm{CNT}$ that drops on the electrode was $1 \mathrm{mg} \mathrm{mL}^{-1}$ ) 


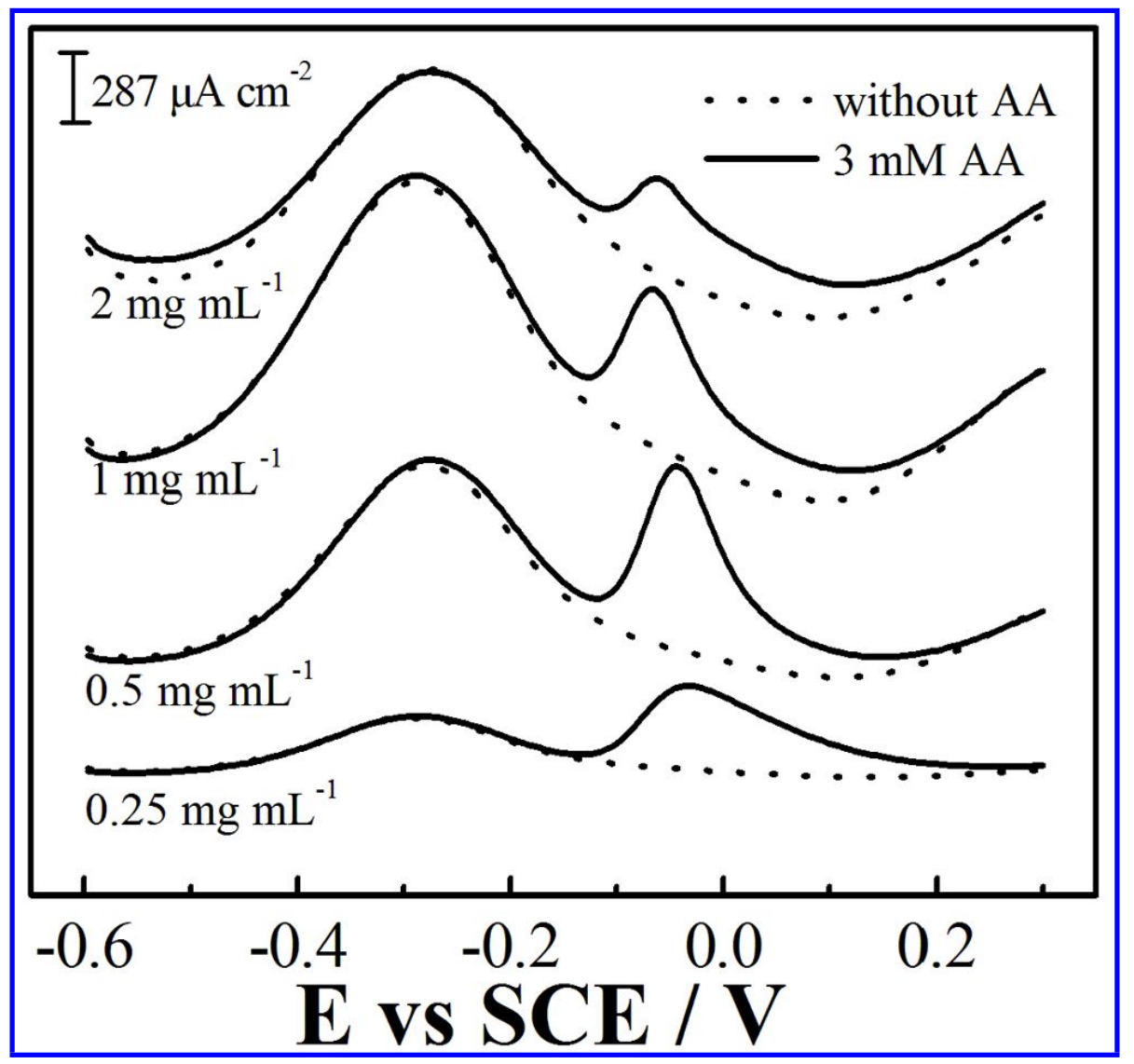

Figure S8. DPV of modified GCE with different concentration of $\mathrm{COF}_{\mathrm{Thi}-\mathrm{TFPB}}-\mathrm{CNT}$ before and after the addition of $3 \mathrm{mM}$ AA.

When the concentration of $\mathrm{COF}_{\text {Thi-TFPB }}-\mathrm{CNT}$ was $0.25 \mathrm{mg} \mathrm{mL}$, there were too less $\mathrm{COF}_{\text {Thi-TFPB }}-\mathrm{CNT}$ on the surface of electrode, so the peak current of both $\mathrm{COF}_{\text {Thi-TFPB }}$ and AA was smaller. The decreased catalytic current when the concentration was more than $0.5 \mathrm{mg} \mathrm{mL}^{-1}$ could be attributed to that excessive $\mathrm{COF}_{\mathrm{Th} \text {-TFPB }}-\mathrm{CNT}$ on the GCE surface would cover some active sites of CNT. 


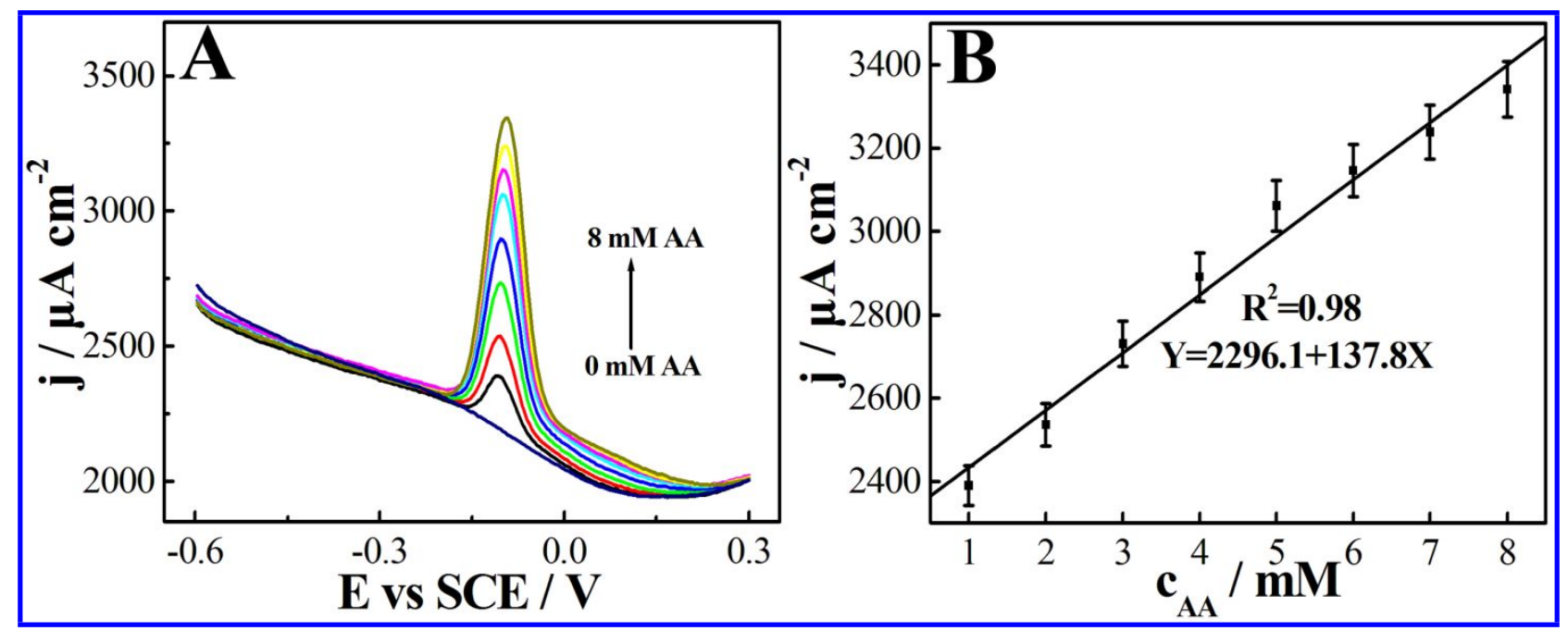

Figure S9. (A) DPV curves of CNT/GCE with different concentration of AA. (B) The corresponding plots of $j$ versus AA concentration. 


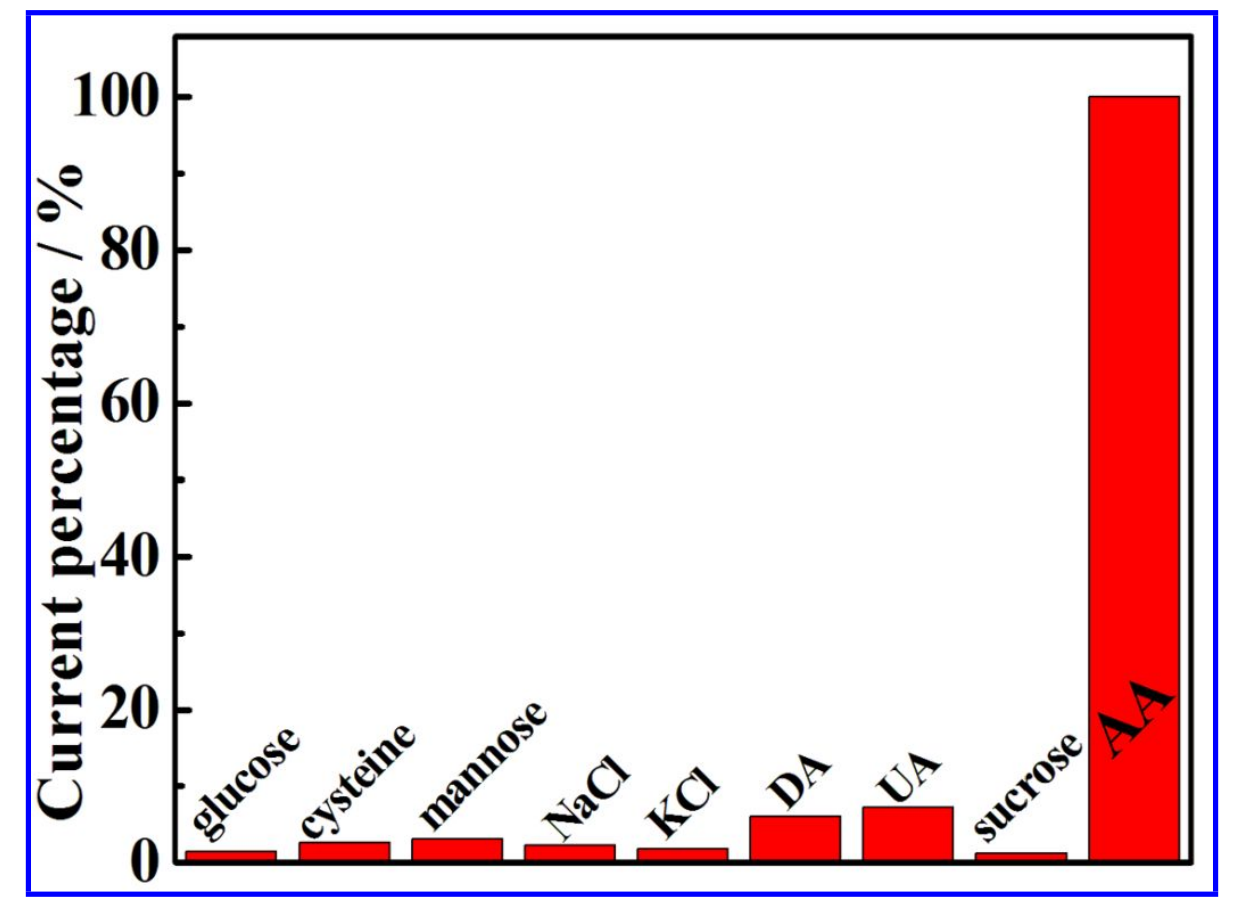

Figure S10. Interference histogram of some substances for AA detection based on CNT/GCE. 


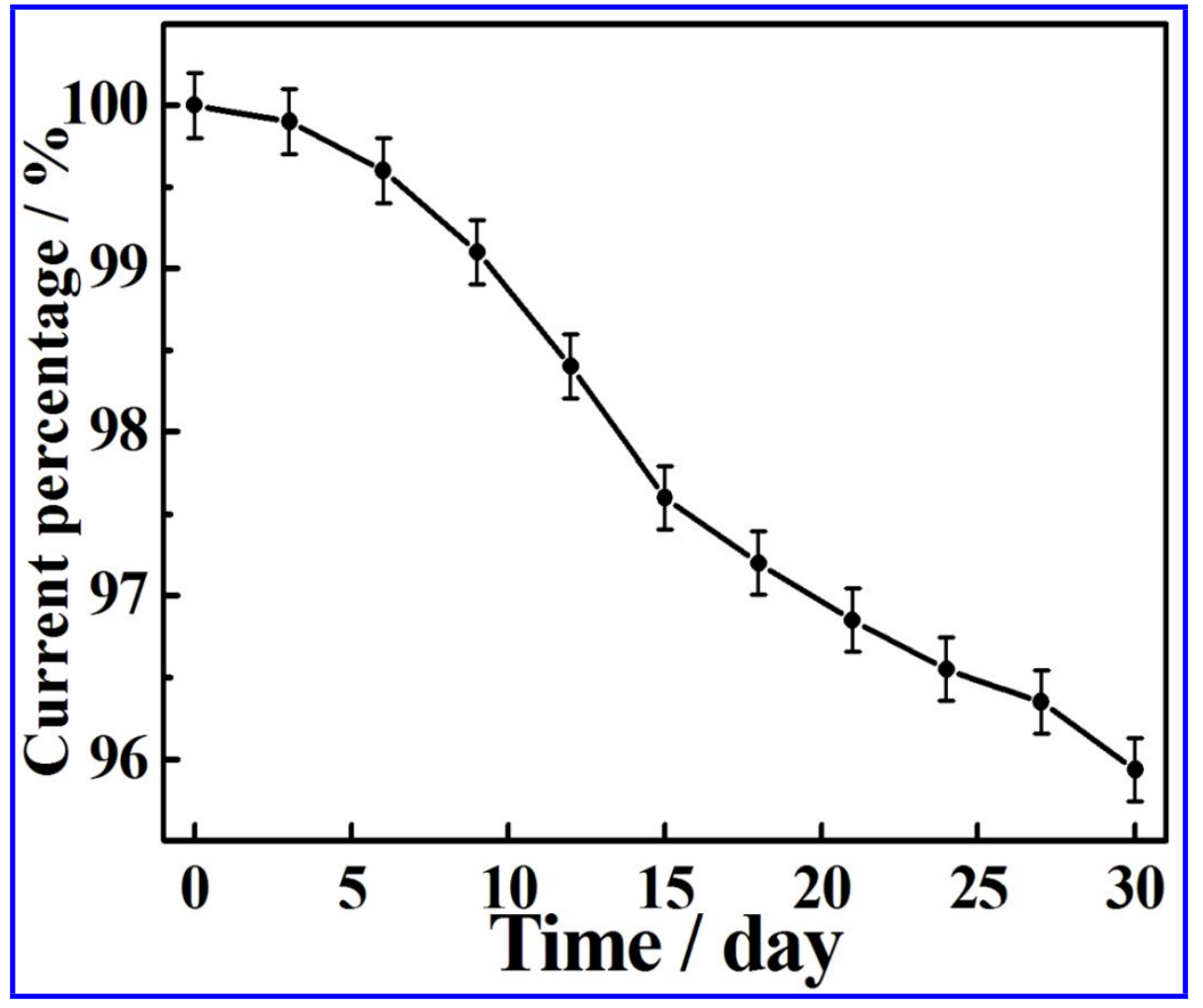

Figure S11. The percentage changes in response of $\mathrm{COF}_{\mathrm{Thi}-\mathrm{TFPB}}-\mathrm{CNT} / \mathrm{GCE}$ toward $2.0 \mathrm{mM} \mathrm{AA}$ in $\mathrm{N}_{2}$-saturated $0.2 \mathrm{M}$ PBS over 30 days. 
Table S1. Comparison of the performance of different $\mathrm{pH}$ sensors

\begin{tabular}{|c|c|c|}
\hline Sensor & Linear range $(\mu \mathrm{M})$ & Reference \\
\hline $\mathrm{COF}_{\text {Thi-TFPB }}-\mathrm{CNT} / \mathrm{GCE}$ & $1.0-12$ & This work \\
\hline GOD+ABTS/SWNT/CFME & $5.67-7.65$ & {$[1]$} \\
\hline CFME/Au/1,2-NQ+FcHT & $5.8-8.0$ & {$[2]$} \\
\hline Hemin-Fc/CNT & $5.5-8.0$ & [3] \\
\hline $\mathrm{CFME} / \mathrm{SWNT} / \mathrm{AQ}+\mathrm{NS}_{4}-\mathrm{C}_{1}+\mathrm{ABTS}$ & $6.0-8.0$ & {$[4]$} \\
\hline PANi-PEDOT-MWCNT & $2.0-12$ & {$[5]$} \\
\hline CF-UME & $2.0-12$ & {$[6]$} \\
\hline $\mathrm{Nafion} / \mathrm{NH}-\mathrm{Co}_{3} \mathrm{O}_{4} \mathrm{NFs} / \mathrm{GCE}$ & $\begin{array}{l}3.0-9.0 \\
9.0-13\end{array}$ & {$[7]$} \\
\hline
\end{tabular}


Table S2. Determination of AA in vitamin C tablets.

\begin{tabular}{cccccc}
\hline Sample & Added & Determined by & Determined by & Recovery & RSD \\
$(\mathrm{mM})$ & AA & standard method & COF $_{\text {Thi-TFPB-CNT }}$ & $(\%)$ & $(\%, \mathrm{n}=5)$ \\
& $(\mathrm{mM})$ & $(\mathrm{mM})$ & sensor $(\mathrm{mM})$ & & \\
\hline & 1.0 & 1.12 & 1.13 & 100.9 & 3.84 \\
0.12 & 1.5 & 1.62 & 1.61 & 98.38 & 4.21 \\
& 2.0 & 2.13 & 2.14 & 100.9 & 3.16 \\
\hline
\end{tabular}




\section{References}

[1] Li, S.; Zhu, A.; Zhu, T.; Zhang, J.; Tian, Y. A Single Biosensor for Simultaneous Quantification of Glucose and $\mathrm{pH}$ in a Rat Brain of Diabetic Model Using Both Current and Potential Outputs. Anal. Chem. 2017, 89, 6656-6662.

[2] Zhou, J., Zhang, L., Tian, Y. Micro Electrochemical pH Sensor Applicable for Real-Time Ratiometric Monitoring of pH Values in Rat Brains. Anal. Chem. 2016, 88, 2113-2118.

[3] Liu, L.; Zhao, F.; Liu, W.; Zhu, T.; Zhang, J.; Chen, C.; Dai, Z.; Peng, H.; Huang, J.; Hu, Q.; Bu, W.; Tian, Y. An Electrochemical Biosensor with Dual Signal Outputs: Toward Simultaneous Quantification of $\mathrm{pH}$ and $\mathrm{O}_{2}$ in the Brain Upon Ischemia and in a Tumor Dduring Cancer Starvation Therapy. Angew. Chem. Int. Ed. Engl. 2017, 56, 10471-10475.

[4] Liu, W.; Dong, H.; Zhang, L.; Tian, Y. Development of an Efficient Biosensor for the in Vivo Monitoring of $\mathrm{Cu}(+)$ and $\mathrm{pH}$ in the Brain: Rational Design and Synthesis of Recognition Molecules. Angew. Chem. Int. Ed. Engl. 2017, 56, 16328-16332.

[5] Smith, R.E.; Totti, S.; Velliou, E.; Campagnolo, P.; Hingley-Wilson, S.M.; Ward, N.I.; Varcoe, J.R.; Crean, C. Development of a Novel Highly Conductive and Flexible Cotton Yarn for Wearable pH Sensor Technology. Sens. Actuators, B 2019, 287, 338-345.

[6] Khani, H.; Wipf, D.O. Fabrication of Tip-Protected Polymer-Coated Carbon-Fiber Ultramicroelectrodes and pH Ultramicroelectrodes. J. Electrochem. Soc. 2019, 166, B673-B679.

[7] Dong, Q.; Wang, X.; Willis, W.; Song, D.; Huang, Y.; Zhao, J.; Li, B.; Lei, Y. Nitrogen-Doped Hollow $\mathrm{Co}_{3} \mathrm{O}_{4}$ Nanofibers for Both Solid-State $\mathrm{pH}$ Sensing and Improved Non-Enzymatic Glucose Sensing. Electroanalysis 2019, 31, 678-687. 